\title{
On the in situ measurement of temperature and electrical conductivity of sea-water
}

\author{
Gerold SIEDLER*
}

(Received 8 February 1963)

\begin{abstract}
After some brief comments on the measurement of temperature and electrical conductivity in oceanography, the measuring probes suitable for in situ measurements are reviewed. Then the method of measurement is described using an improved model of the so-called bathysonde. This makes possible a continuous recording of temperature, conductivity, and pressure with high accuracy in great depths. Measurements from the Skagerrak and from the Mediterranean are ccnsidered. Finally, problems are discussed which arise when evaluating electrical conductivity and temperature from in situ measurements.
\end{abstract}

\section{INTRODUCTION}

ONE of the most important problems in physical oceanography is the determination of density and sound velocity in sea water. Indirect methods use the values for temperature and salinity-the latter being derived from the chlorinity - or the values for temperature and electrical conductivity. Recent investigations by Cox et al. (1962) have shown that a greater accuracy in the density determination is achieved with conductivity than with chlorinity measurements. By accident, because of the technical possibility of measuring temperature and conductivity in situ, several institutes have been using these two parameters for density determination for a number of years. Depending on the different requirements of the particular oceanographic problem to be solved and of the sea area to be surveyed different types of instruments have been developed. The general aim is a device which, by the use of telemetering techniques, simultaneously with in situ measurements, records, and possibly even evaluates the data on shipboard or in a laboratory ashore.

As telemetering in situ temperature measurements always implies transforming the measured values into electrical signals an electrical thermometer is usually used. An exception is the technique used by JOSEPH (1962) with the 'Delphin' where the movement of a capillary tube spring, filled with a temperature sensitive liquid, was transformed by mechanical scanning into a variation of the time interval between electrical impulses.

The usual measuring probes are metal resistance thermometers, thermistors, and thermoelements. The thermoelements are only used in those cases where a fast time response with a good relative, but less absolute, accuracy is required (KALLE, 1942; 1953), but generally a high absolute accuracy is needed to detect long-term variations in the structure of water masses. For this reason metal resistance thermometers and thermistors are preferred. Quite often thermistors are chosen for continuous recordings because, due to their high temperature dependence, they can easily be used in electrical circuits (ANDERSON and BURKe, 1951; MorTIMER and MOORE, 1953; DORRESTeIN 1954; Hamon 1955; Pritchard 1959; German 1960; Williams 1961; Booker 1961). One disadvantage is the insufficient constancy of the resistance value of the thermistor, so that measurements with an accuracy of more than about $\pm 0.05^{\circ} \mathrm{C}$ can be achieved only with frequent calibration tests, If good constant readings are wanted over a long period, the best method is to use a platinum resistance element (HINKELMANN, 1956; 1957) as in the so-called bathysonde. It is possible to obtain the very small thermal time constant of $0.16 \mathrm{sec}$ with a special design. The disadvantage when compared with the thermistor is the small temperature coefficient of the platinum wire, which therefore requires a more sensitive electrical circuit.

*Institut für Meereskunde, Kiel University, Germany. 
There are three methods of measuring electrical conductivity, each distinguished by the mannet of coupling the solution to the measuring circuit: The eletrode, the capacitive, and the inductive method. Capacitive coupling with high frequency is only known in measurements in the laboratory (HUEBNER, 1959) whereas coupling with electrodes was the most usual procedure at first with in siriti measurements (JACOBSON, 1948; Dorrestein, 1954; Hamon, 1955; Esterson, 1957; Schiemer and PrITCHARD, 1957). One advantage is the direct transformation of the conductivity of the sea-water into a measurable resistance; the most important disadvantage is the dependence of the measurement on the condition of the electrode surface. Electrode assemblies may be used with in situ measurements up to an absolute accuracy of about $0 \cdot 110^{-3} \Omega^{-1} \mathrm{~cm}^{-1}$. For a higher accuracy over a longer period the contamination of the electrodes is so great in the open sea that only the inductive method can be used. It has been used for this purpose by Esterson (1957), Hinkelmann (1958), Pritcharo (1959), German (1960), Williams (1961) and Brown (1961).

The author has worked since 1958 with several types of bathysonde (HINkELmanN, 1956, 1957, 1958; KROEBEL, 1961) in different sea areas (SIEDLER, 1961). As we have now obtained successful measurements of temperature and electrical conductivity even from great depths, it seems desirable to describe the present state of the technical development of this device and to discuss the problems. arising in the evaluation of its records.

In order to obtain a direct record of temperature and electrical conductivity as a function of depth. the device in addition to the temperature and conductivity probes has a Bourdon tube to measure the hydrostatic pressure. The three measuring probes for temperature, conductivity and pressure are frequency-determining parts of three oscillator circuits which work respectively within the ranges 0.86 to $1.5 \mathrm{kc} / \mathrm{s} ; 2.57$ to $4.5 \mathrm{kc} / \mathrm{s}$ and 6 to $9 \mathrm{kc} / \mathrm{s}$. To avoid the use of multiconductor cables, as their weight requires a big winch for work at great depths, an especially developed single conductor cable was used to carry the underwater unit (SIEDLER, 1962) with the current returning to the ship through the sea water. The frequency signals are transmitted back to the ship over the single conductor cable and are either recorded on a magnetic tape recorder or transformed into d.c.-current. Thus, the dependence of the temperature and conductivity on the pressure, i.e., on the depth, can then be recorded on a double-function X-Y-recorder. In order to use the instrument in any oceanic area the following ranges and accuracies were required :

$$
\begin{aligned}
& \text { temperature : }-2 \text { to }+35 \mathrm{C} ; \pm 0.02^{\circ} \mathrm{C} \\
& \text { electrical conductivity : } 20 \text { to } 7010^{-3} \Omega^{-1} \mathrm{~cm}^{-1} ; \pm 0.0210^{-3} \Omega^{-1} \mathrm{~cm}
\end{aligned}
$$

This means that for $10^{\circ} \mathrm{C}$ and a salinity of $35 \%$ there is an accuracy of $\pm 0.04 \%$. If all frequency determining components of the oscillators which are temperature sensitive are installed in a thermostat, the frequency error of the oscillators is less than 1 per cent of the frequency range. To achieve the accuracy of $\pm 0.02^{\circ} \mathrm{C}$ and $\pm 0.0210^{-3} \Omega^{-1} \mathrm{~cm}^{-1}$, the range had to be subdivided. This sub. division can be made (1), in the oscillators and (2), before or (3), after the frequency measurement in the shipboard portion of the instrument. The first provides the greatest and the third the least increase in accuracy. Frequency signals are used to make the switch in the oscillators by remote control when lowering the underwater unit. As this requires some technical care only as many steps for subdividing the range are made in the underwater device as are really necessary; others can be made on shipboard before the frequency measurement. The Kieler Howaldtswerke constructed an instrument (FIG, 1) according to specifications provided by the Institut für Meereskunde, Kiel. The underwater unit had 10 switch positions each, for temperature and conductivity. Position 1 covered the whole range $\left(-2\right.$ to $f 35^{\circ} \mathrm{C} ; 20$ to $\left.7010^{-3} \Omega^{-1} \mathrm{~cm}^{-1}\right)$, positions 2 to 9 overlapping sub-ranges. The changeover was made on shipboard by switching the transmitter to combinations of the five frequency signals of $10 \cdot 5-12 \cdot 0-13 \cdot 7-15 \cdot 6-17 \cdot 8 \mathrm{kc} / \mathrm{s}$. The pressure oscillator was not switched because hysteresis and the temperature dependence of the Bourdon tube limited the accuracy of the pressure reading to about 1 per cent. The three frequencies for temperature, conductivity, and pressure are separated on board with filters. To achieve a high relative frequency shift $\left(f_{2}-f_{1}\right) / f_{1}$, the following method is used The frequency of the temperature oscillator $(0.86$ to $1.5 \mathrm{kc} / \mathrm{s})$ is multiplied by 3 to get the same range as the conductivity oscillator $(2.57$ to $4.5 \mathrm{kc} / \mathrm{s})$. Using five overlapping sub-ranges $(2429-2945 ; 2842$ $3358 ; 3255-3771 ; 3668-4184 ; 4081-4597 \mathrm{c} / \mathrm{s}$ ) the two frequencies for temperature and conductivity are heterodyned to the range 363 to $879 \mathrm{c} / \mathrm{s}$. After transformation of the resultant frequencies into d.c. current the measured values are recorded on a double-function $X-Y$ recorder. The original frequencies may, however, also be fed directly into a digital computer. 
The first tests, thanks to the kind assistance of the Oceanografiska Institutet, Göteborg, could be carried out in the Gulmarfjord. These tests and the first measurements of the thermohaline layering with this instrument in the Skagerrak and Kattegat on board the research cutter Hermann Wattenberg,

UNDERWATER UNIT

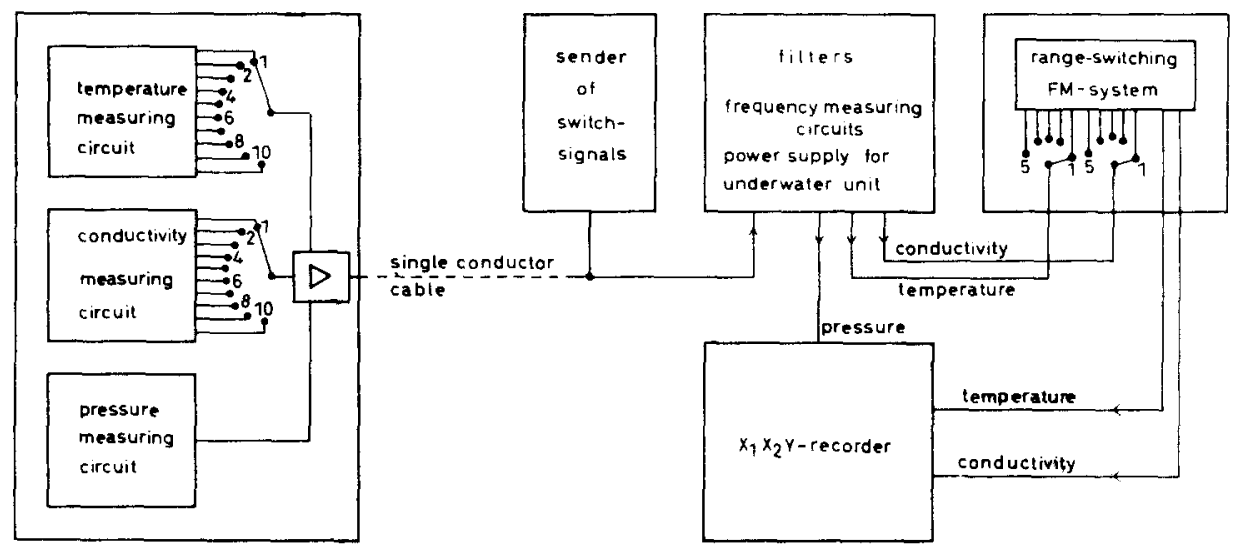

FiG. 1. Block diagram of the bathysonde.

Kiel University, proved the usefulness of the method. FiG. 2 is an example of the temperature record in the Skagerrak. On the left is shown the record with a large range (1/2 means switch-position 1 for the whole range in the underwater unit and switch-position 2 for the second sub-range in the shipborne unit), and on the right the record made on the next lowering with several sub-ranges from the same locality. Naturally, in an area with such a strongly variable layering the less accurate but more conspicuous measurement will generally be preferred. The first measurements in the deep-sea in the Mediterranean could be made, thanks to the Bureau d'Études Océanographiques, Toulon, on board the French research ship Origny. The maximum depth $(2000 \mathrm{~m})$ was not reached because the cable used only allowed measurements down to $1600 \mathrm{~m}$ depth.

FIG. 3 is an example of the record of temperature and conductivity. As the variations with depth are very large in the upper $50 \mathrm{~m}$, the large range $1 / 3$ was used for the temperature and for the conductivity. To get an idea of the fine structure of the layering in greater depths one small range was used from 50 to $1600 \mathrm{~m}$. Thus records were obtained with optimum adaptation to existing conditions. FIG. 4 compares temperatures measured on lowering and on raising the bathysonde. Great differences are apparent in the temperature layers between measurements made within a half hour at nearly the same place even in the deep sea (Station No. 27, $43^{\circ} 28^{\prime} \mathrm{N}, 7^{\circ} 28^{\prime} \mathrm{E}, 18$ May 1962).

All measurements with the bathysonde were compared with those obtained with reversing thermometers and Nansen-bottles. These were evaluated by the author at the Institut für Meereskunde, Kiel University. Those obtained in the Mediterranean were also evaluated by PeLUCHON, Bureau d'Études Océanographiques, Toulon, and by Hinkelmann, Institute for Applied Physics, Kiel University. Since the measurements with the bathysonde and the Nansen-bottles were not made at exactly the same time, they were not absolutely identical because of the slight drifting of the ship and due to fluctuations in the temperature layers in the interval between the two types of observation. Furthermore, it was impossible to decide whether the two measurements to be compared came from exactly the same depth because the Nansen-bottle depth was determined on the one hand by the wire length together with the wire angle at the sea surface and on the other hand the bathysonde depth was based on the pressure record. In the upper $500 \mathrm{~m}$, however, differences of about $20 \mathrm{~m}$ have a marked effect on the errors incurred. Considering the sources of these errors, one may conclude from the records already on file that the deviation of the temperature recorded with the bathysonde 


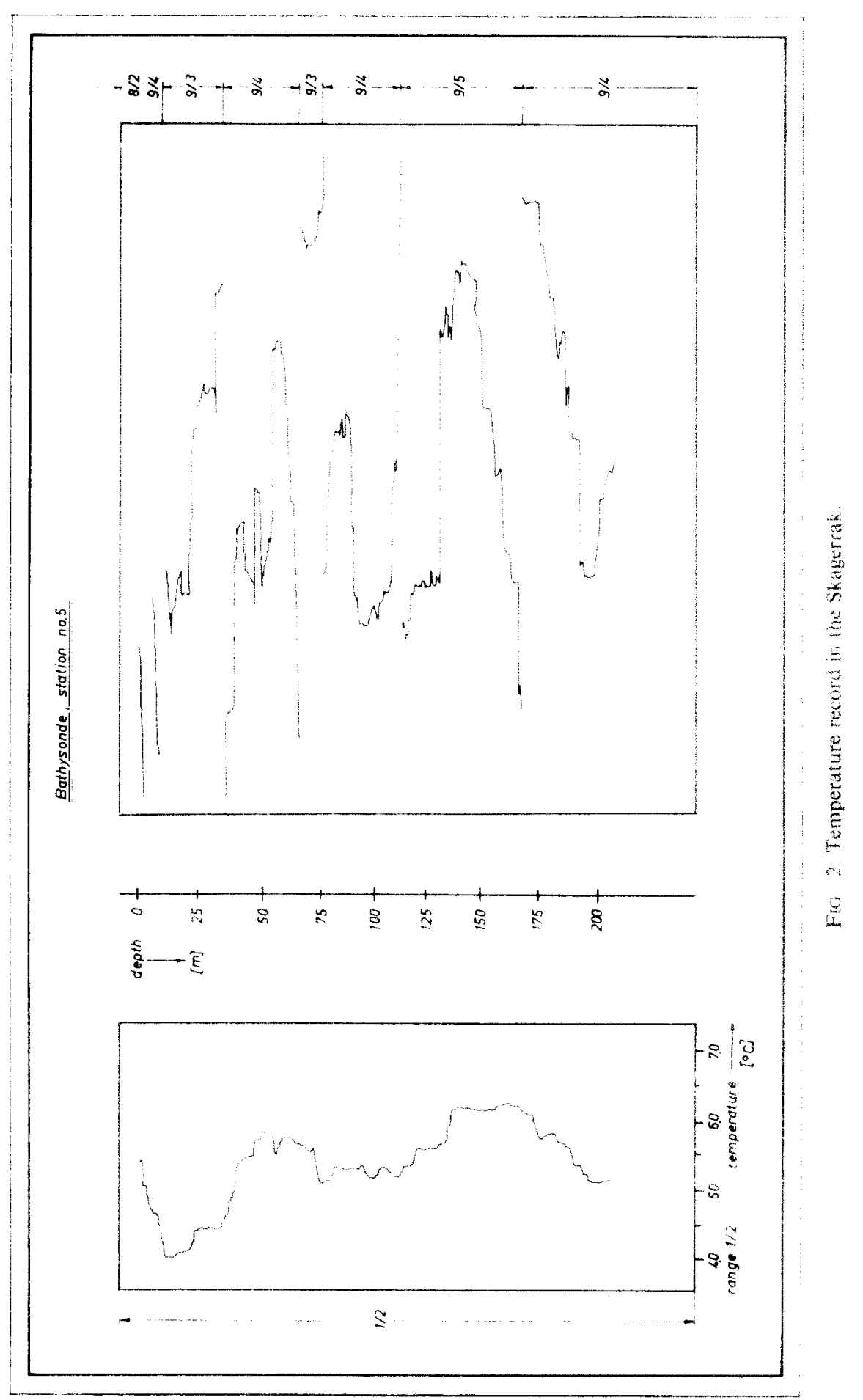




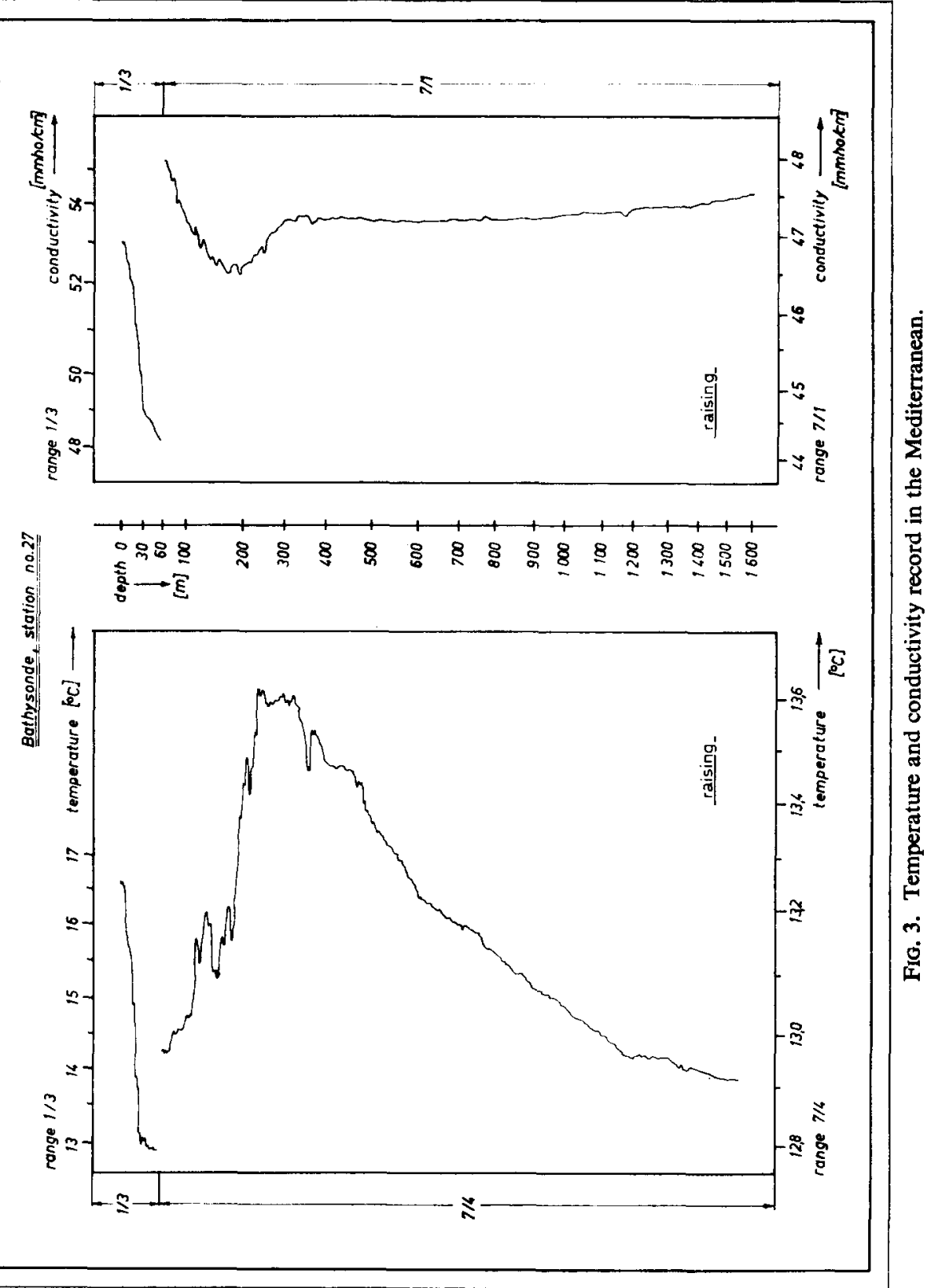




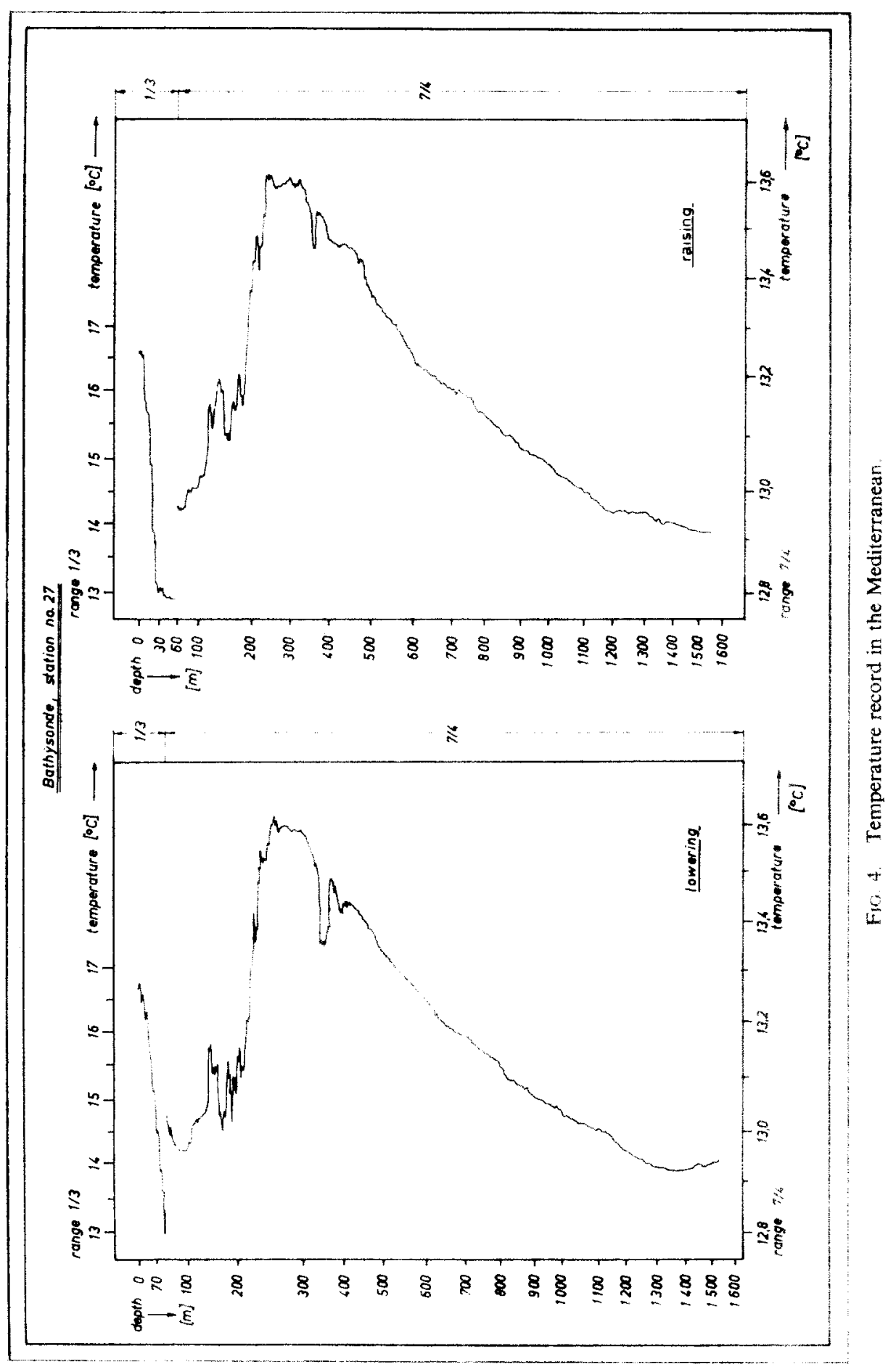


from that with reversing thermometers is less than $0.02^{\circ} \mathrm{C}$ if the calibration curve is corrected by $0.03^{\circ} \mathrm{C}$. This correction is necessary because apparently the temperature measuring circuit is not yet stable enough for longer periods (i.e. months). Test series are now being carried out to show the exact value of this frequency drift to explain the causes for these deviations. Of course, the usefulness of these measurements is not limited as long as the calibration corrections are based on a number of comparative measurements.

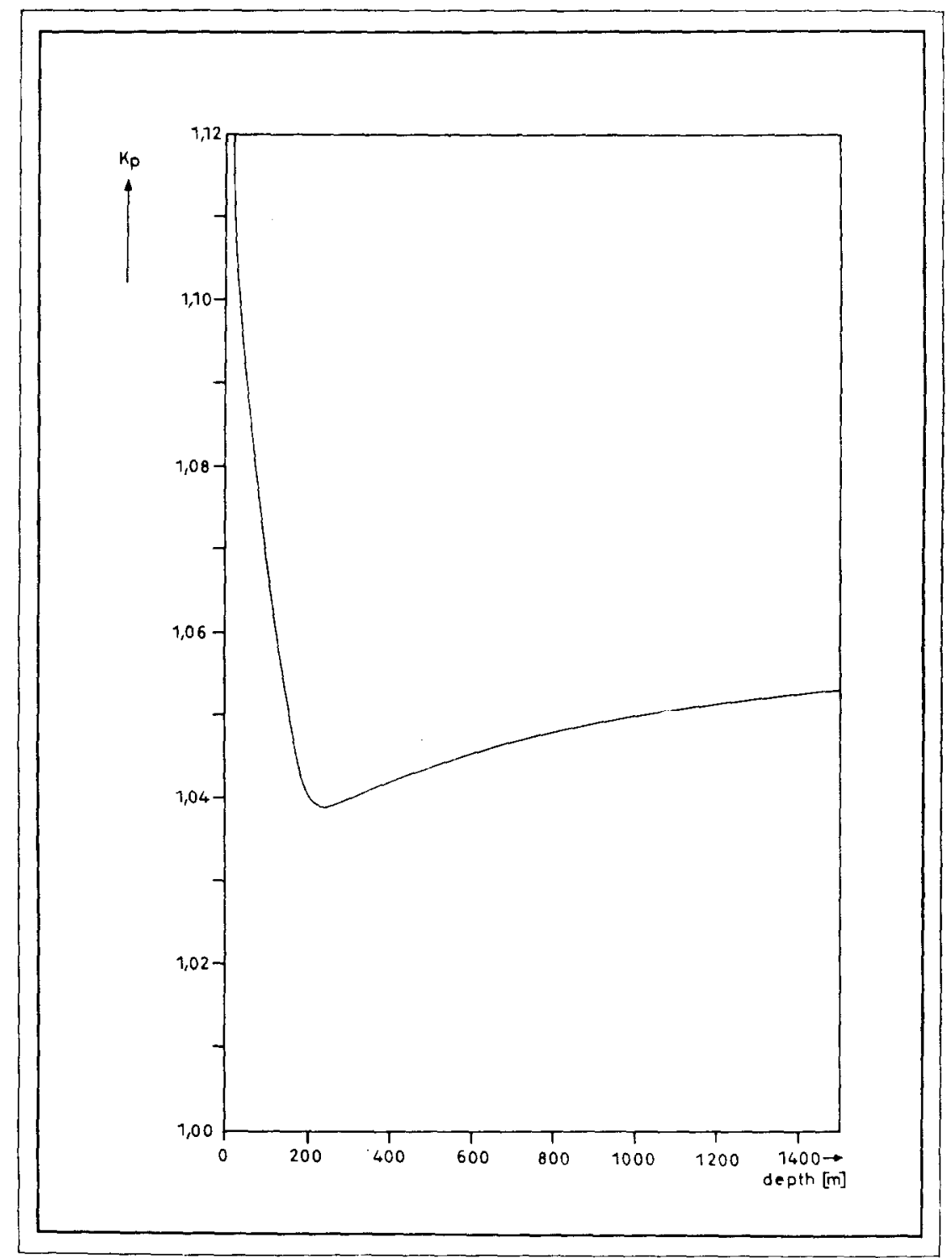

Fig. 5. Pressure dependence factor $K_{p}$ of the bathysonde.

Evaluation of the conductivity records is much more difficult. It will not suffice to consider only the statements of Thomas et al. (1934), and BEIN et al. (1935) about the dependence of the electrical conductivity on temperature and salinity, because with in situ measurements their dependence on 
pressure must also be considered. This problem has been investigated by several others (HAMON 1958; Bradshaw 1962; Hornf and Frysinger, 1963), but as yet no definitive measurements have been made. Despite this a first impression of the usefulness if the in situ conductivity measurements can be obtained with the following formula derived from BRADSHAw's tentative results which was used as an approximation for the evaluation of the measurements carried out in the Mediterranean:

$$
C_{p}=C_{i} \quad 1 \cdot 2 \therefore 10^{-4} S p
$$

$C_{p}$ is the conductivity in $10^{-3} \Omega^{-1} \mathrm{~cm}^{-1}$ under the pressure $p ; C_{1}$ is the conductivity in $10^{-5} \mathrm{~cm}$ under the pressure $1 \mathrm{~atm}$, calculated from the data of ThOMAs, THOMPSON and UTterbaCk (1934); $S$ is the salinity in $\% ; p$ is the pressure in $\mathrm{kg} / \mathrm{cm}^{2}$. As the conductivity probe also proved to be dependent on pressure the following formula was finally used :

$$
C_{r} \cdots K_{p} \cdot C_{p}
$$

$C_{r}$ is the recorded conductivity; $K_{p}$ is the factor which indicates the pressure dependence of the probe itself. One thus obtains :

$$
C_{r} \cdot K_{p}\left(C_{i} \quad 1 \cdot 2 \times 10^{-4} S p\right)
$$

$K_{p}$ was determined using all available measurements (FIG. 5). FIG. 6 represents the recorded con ductivity $C_{r}$ (in simplified form, see FIG. 3), of the conductivity $C_{1}$-calculated for the neasuring points of the Nansen-bottles and of the corrected conductivity $C_{1 k}$, calculated from equation (3):

$$
C_{i k}=\frac{C_{r}}{K_{p}}-1 \cdot 2 \cdot 10^{-4} S p
$$

It is possible to correct the recorded conductivity and to use if together with the temperature as a basis for the calculation of density. However, the same accuracy of $0.0210^{3} \Omega^{-1} \mathrm{~cm}^{-1}$ observed for atmospheric pressure cannot yet be obtained for in situ measurements as $K_{p}$ is not yet exactly known. Since the measurements described above were made, the manufacturers of the bathysonde have begun tests, aimed at reducing the influence of the factor $K_{p}$ by a re-design of the conductivity sonde and thus simplifying the evaluation of the conductivity recordings.*

The present state of the technique described is that with the improvements mentioned, we calt now record temperature and electrical conductivity continuously down to a depth of $2000 \mathrm{~m}$ within a short period. The resetability of temperature measurement is better than $\pm 0.02 \mathrm{C}$, that for electrical conductivity is expected to be better than $\leqslant 0.0210^{-3} \Omega^{-1} \mathrm{~cm}^{-1}$, and that for pressure equalling about 1 per cent of the total depth range.

A study of the measurements made up to this point indicates that the in situ measurements involve problems to be solved, which, on the one hand, are dependent on our knowledge of fundamental relationships in sea water, and which, on the other hand, are connected with practical difficulties in the measuring technique used. Investigations to solve these problems are under way. Measurements on the pressure dependence of conductivity are being carried out or planned at several institutions (among others, Kiel University), and the relation between density and electrical conductivity have already been investigated in Great Britain by Cox, et al. Further technical improvement of the system used in the bathysonde will also be continued. As mentioned before, test series are being made at the moment to elucidate and to eliminate the drift of the temperature calibration. Furthermore, an attempt is being made to reduce the effect of the factor $K_{p}{ }^{*}$ The increased accuracy of in situ measurements in the future will depend on how soon these problems can be solved.

*The first tests of the re-designed conductivity sonde carried out by KROEBEL and KRAUSE in April 1963 showed that there is almost no pressure dependence of $K_{p}$ when using this new probe.

$$
\text { REFIRENCES }
$$

Anderson, E. R., and Burke, A. T. (1951) Notes on the development of a thermistor temperature profile recorder. J. Mar. Res. 10 (2), 168-179.

Bein, W., HirsekorN, H. -G. and Möller, L. (1935) Konstantenbestimmungen des Meerwassers und Ergebnisse über Wasserkörper. Veroff. Inst. Meereskunde, Berlin, (A), 28, 240 pp.

BOoker, P. G., (1961) New sea temperature measuring devices. J. du Cons., 26 (2), 133-147.

Bradshaw, A. L. (1962) Unpublished tentative results about the effect of pressure on conductivity. 


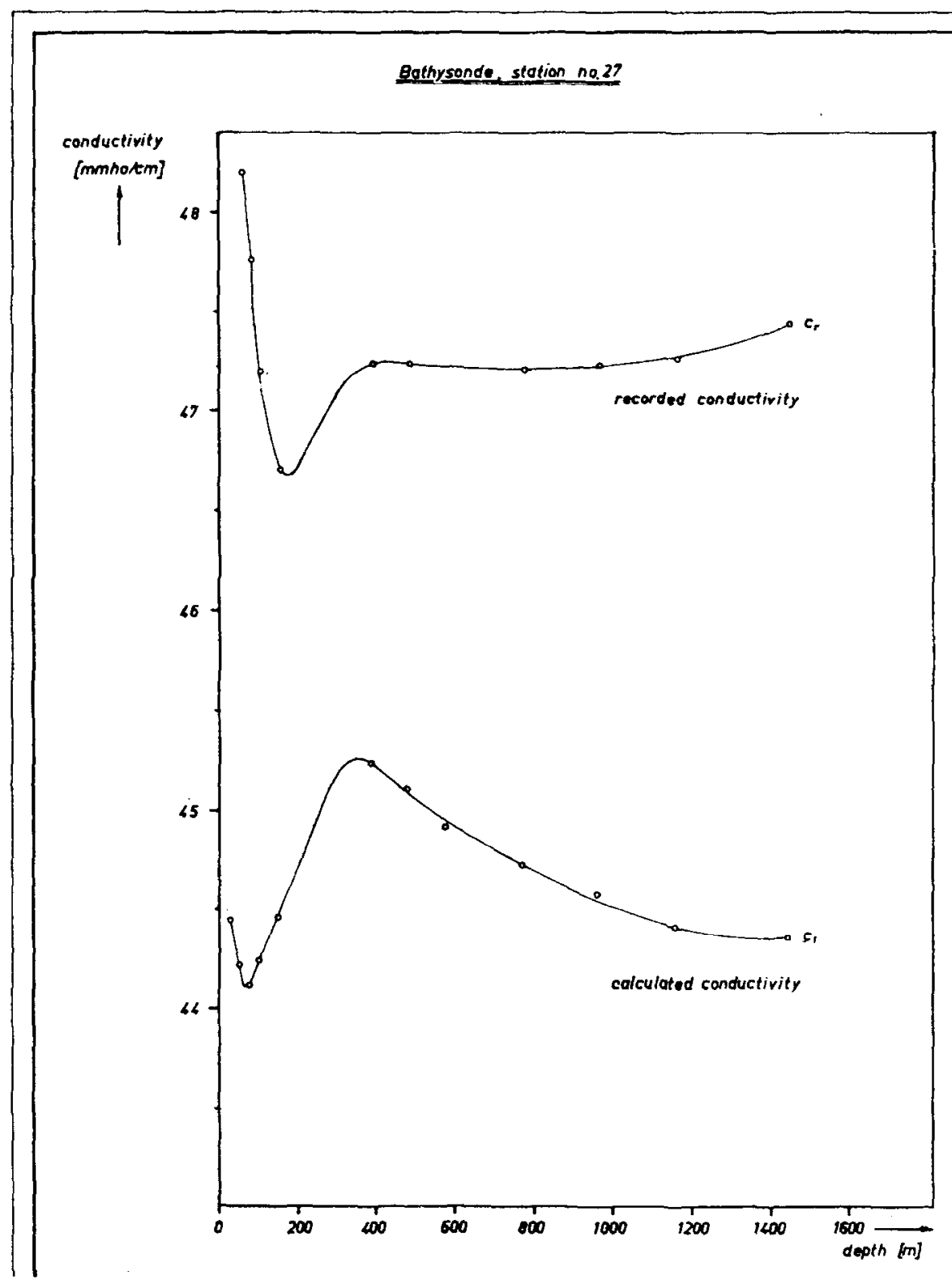




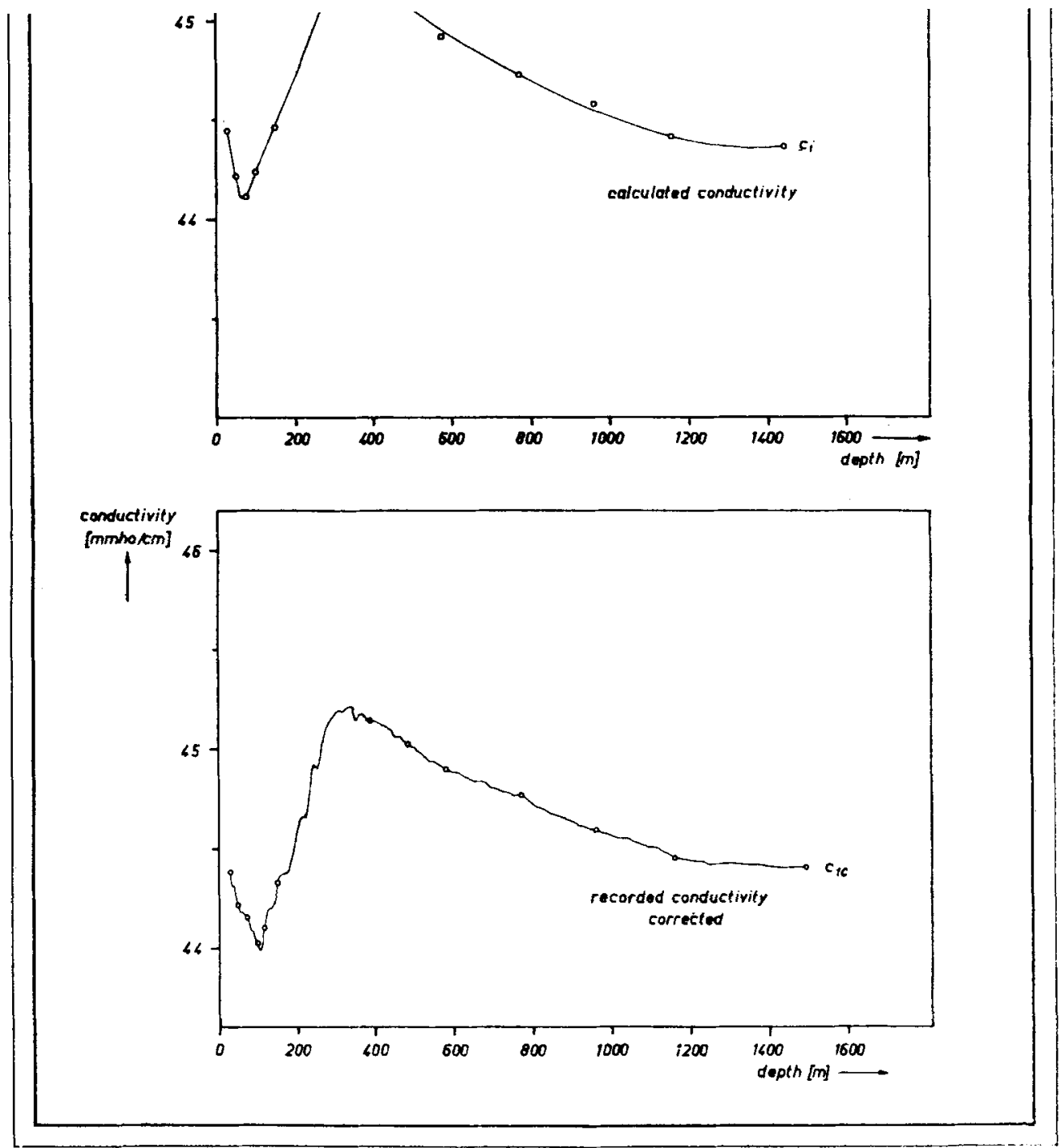

FIG. 6. Recorded conductivity $C_{r}$, calculated conductivity $C_{1}$ and corrected conductivity $C_{1 k}$. 
Brown, N., (1961) Unpublished report about the salinometer constructed at the Woods Hole Oceanographic Institution. Symposium on the in situ measurement of salinity and temperature in the sea, National Institute of Oceanography, Wormley.

Cox, R. A., Culkin, F., Greenhalgh, R. and Riley, J. P. (1962) Chlorinity, conductivity and density of sea-water. Nature, Lond. 193 (4815), 518-520,

DorresteIn, R. (1954) Een registrerende electrische Zoutgehalteen Temperatuurmeter voor Gebruik op Zee. Meded. en Verh. Kgl. Nederl. Meteorol. Inst., 59, 387-402.

Esterson, G. L. (1957) The induction conductivity indicator, a new method for conductivity measurement at sea. Chesapeake Bay Inst. Tech. Rept., 14. (Unpublished manuscript).

Esterson, G. L. and Pritchard, D. W. (1955) C.B.I. salinity-temperature meters. Proc. First Conf. Coastal Engrg. Instruments, Council on Wave Res., The Engrg. Foundation, 260-271.

German, J. C. (1960) An inductive salinity meter for in situ measurements. J. du Cons., 26 (1), 21-32.

HamoN, B. V. (1955) A temperature-salinity-depth recorder. $J$. du Cons, 26 (1), 72-73.

Hamon, B. V. (1958) The effect of pressure on the electrical conductivity of sea-water. J. Mar. Res., $16(2), 83-89$.

Hinkelmann, H. (1956) Ein Gerät zur Schnellregistrierung des Druckes, der Temperatur und des Salzgehaltes für Anwendungen in der Ozeanographie. Kiel. Meeresf. 12 (2), 200-201.

Hinkelmann, H. (1957) Gerät zur Schnellregistrierung in der Ozeanographie. Z. Angew. Physik, $9(10), 505-513$.

Hinkelmann, H. (1958) Ein Verfahren zur elektrodenlosen Messung der elektrischen Leitfähigkeit von Elektrolyten. Z. Angew. Physik, 10 (11), 500-503.

Horne, R. A. and Frysinger, G. R. (1963) The effect of pressure on the electrical conductivity of sea water. J. Geophys. Res. 68 (7), 1967-1973.

Huebner, G. L. (1959) Note on radio frequency salinity measuring equipment at Texas A.a.M. College. Conf. on physical and chem. properties of sea water. Nat. Acad. Sci-Nat. Res. Counc., Publ. 600, 155 .

JACOBSON, A. W. (1948) An instrument for recording continuously the salinity, temperature and depth of sea water. Trans. Amer. Inst. Electr. Engrs., 67, 1-9.

JoSEPH, J. (1962) Der "Delphin", ein Messgerät zur Untersuchung von oberflächennahen Temperaturschichtungen im Meere. Deutsch. IIydrogr. Zeits., 15 (1), 15-23.

KALLE, K. (1942) Über die innere thermische Unruhe des Meeres. Ann. Hydrogr. u. Marit. Meteorol., $70(12), 383-387$.

Kalle, K. (1953) Zur Frage der inneren thermischen Unruhe des Meeres. Deutsch Hydrogr. Zcits. $6(4 / 5 / 6), 145-170$.

Kroebel, W. (1961) Zur Messmethodik von ozeanographischen Sondenmessgeräten. Kiel. Meeresf. 17 (1), 17-24.

Mortimer, C. H. and MOORE, W. H. (1953) The use of thermistors for the measurement of lake temperatures. Int. Vereinigung Theor. u. Angew. Limnologie, Mitteilungen, 2.

Pritchard, D. W. (1959) The in situ measurement of salinity with the induction-conductivity indicator. Conf. on physical and chemical properties of sea water. Nat. Acad. Sci.-Nat. Res. Counc., Publ. 600, 146-154.

Schifmer, E. W. and Pritchard, D. W. (1957) The Chesapeake Bay Institute conductivity-temperature-Indicator. Chesapeake Bay Inst. Tech. Rept., 12. (Unpublished manuscript).

SIEDLER, G. (1961) Uber die kurzfristige Veränderlichkeit von Temperatur- und Salzgehaltsschichtung in der östlichen und mittleren Ostsee im Sommer 1960. Kiel Meeresf. 17 (2), 148-153.

SiedLer, G. (1962) Die Zugbeanspruchung des Einleiterkabels bei Bathysondenmessungen in der Tiefsee (Technischer Bericht). Kiel. Meeresf. 18 (1), 34-35.

Thomas, B. D., Thompson, T. G. and Utterback, C. L. (1934) The electrical conductivity of sea water. J. du Cons., 9 (1), 28-35.

Williams, J. (1961) A small portable salinometer. Chesapeake Bay Inst. Tech. Rept., 23, (Unpublished manuscript). 